\title{
REFLECTION OF GLOBAL LEARNING AND DEVELOPMENT TRENDS IN OFFICIAL NARRATIVES OF CANADIAN CORPORATIONS
}

\author{
Halyna Nosulich \\ Lviv Polytechnic National University, Lviv, Ukraine \\ halyna.a.nosulich@lpnu.ua \\ Nataliya Mukan \\ Lviv Polytechnic National University, Lviv, Ukraine \\ nataliya.v.mukan@lpnu.ua
}

\begin{abstract}
The paper dwells on how current L\&D trends are followed by Canadian corporations and what their attitude to continuous learning is, considering that corporate narratives present in official documentation are relevant object for the research. In general, scientific inquiry of Canadian experience in the sphere of corporate education is relevant for comprehensive analysis as Canadian best practices can be applied by organisations of various types in other countries. The paper presents quantitative and qualitative data revealed in the process of content analysis of official narratives, their interpretation and correlations between the results and current L\&D trends as outlined in the literature review. Thus, in the centre of the methodological framework of this research is content analysis. 21 general annual and sustainability reports of 13 Fortune 500 Canadian companies were sampled for extracted text narratives to be coded according to the predefined coding scheme and further interpreted. The research has allowed to answer the question whether official documentation issued by Canadian companies is resourceful for the study of corporate education in the country. The light was shed on types of reports which contain the most relevant information on the issue. The investigation revealed that the most frequent coded narratives are related to the continuous development of employees, alignment of L\&D and business strategy, compliance training and inclusion \& diversity training within organisations. The paper describes and discusses these results in detail as well as traces reflection of global L\&D trends in corporate documentation.
\end{abstract}

Keywords: learning and development; trends; official narratives; coding scheme; Canada.

\section{Introduction}

Globalisation and rapid change are among the most important attributes of today's world. The successful development of any sphere, be it social or scientific one, depends on its ability to keep up with changes at the local and global levels preliminarily due to international and interdisciplinary connections between various domains. Corporate learning and development $(L \& D)$ is not an exception. As human capital is the most valuable asset to any organisation which strives for success, effective L\&D function is a key to high performance and growth of a company in a competitive global market. Therefore, it is important to understand the trends in the sphere, particularly the global ones, and what is more important, follow them to achieve desired results.

The present research is an attempt to define the most important L\&D trends at the global scale as followed by Canadian companies via content analysis of their official documentation. Canada is a country with one of the most developed economies in the world ranked $14^{\text {th }}$ in the Global Competitiveness Index by the World Economic Forum 2019 (Schwab, 2019) with a complex and diverse system of corporate education which is significantly supported at the governmental level. In view of this, scientific inquiry of Canadian experience in the sphere of corporate education is relevant for comprehensive analysis as Canadian best practices can be applied by organisations of various types in other countries.

Since corporate narrative analysis allows studying the whole range of organisational phenomena (MerklDavies and Brennan, 2011), analysis of official documentation of Canadian companies will shed the light on the state of L\&D industry in the country. Content analysis is the most popular research method in corporate narratives research as it allows to analyse the disclosed data in terms of quality and quantity (Hossain, 2017). Some researchers emphasise that corporate narratives have to be analysed through the prism of meaning and language with means of discourse analysis (Craig and Brennan, 2012; Higgins \& Walker, 2012; Scharf and Fernandes, 2013). Though the authors of this paper share the same view, this paper focuses on the content analysis of reports by Canadian organisations leaving their discourse analysis for further research.

Review of studies on L\&D trends. The study of trends in the corporate L\&D field is intrinsically interdisciplinary and multi-dimensional. Influenced by a variety of socio-economic factors, it should be considered through the prism of adult learning, lifelong learning, human resources development, and people 
management research. To define the most important tendencies in corporate training, a reference to such authoritative L\&D organisations as the Association for Talent Development (ATD) and Chartered Institute of Personnel and Development is required. Additionally, global trends in corporate L\&D are tracked and analysed by a number of world-leading learning providers who consolidate data from millions of learners and a big number of corporate clients.

The latest research of the Association for Talent Development revealed that L\&D organisations, especially in North America, increasingly focus on such issues as alignment of strategies for workplace learning with business goals, increasing investment in employees' development, importance of closing interpersonal skill gaps, keeping up with changes and enhancing digital literacy and constant lack of time for learning activities (ATD, 2019). Other global corporate education trends are increasing investments in the sphere, importance of managerial involvement in the process of subordinates' learning, importance of marketing efforts to popularise learning activities (ATD, 2019; LinkedIn Report, 2019; Coursera for Business, 2018).

Among the most authoritative online learning providers is Coursera with 33 million registered users and 1800 enterprise clients worldwide. Based on analysing the vast data from learners at workplace, the company defined 21 insights for effective functioning of $L \& D$ organisations constituting corporate education trends worldwide (Coursera for Business, 2018). LinkedIn Learning is another global forerunner in the industry of online learning having access to data on learning activities of 17 million of enterprise users in 14 thousand companies (Bersin, 2018).

Continuous development of competencies through learning is an integral part of professional work (Billet et al., 2014, p. xviii) and understanding importance of continuous learning and building culture of lifelong learning within an organisation is the most consistent global L\&D trend (Coursera for Business, 2018) as well as understanding the needs of employees for enabling self-directed learning (LinkedIn Learning, 2019, p.32). According to Knowles (1975), self-directed learners are responsible for their development and thus, should be able to select learning activities to meet specific learning needs. The activities, however, are provided to the learner at workplace by the company and this is the task of L\&D function to make such selection relevant and qualitative. This is directly related to continuous learning which, according to Tannenbaum (1997), is particularly enhanced by a diverse selection of learning opportunities at workplace. Self-directed learning trend in the system of corporate education can be also associated with transformational leadership theory (Bass, 1991) which defined the relationship between managers and subordinates, when employees, inspired by organisational leaders, bare their own responsibility for their professional development.

Ongoing skills assessment complementing self-directed learning is the most effective approach to developing workforce (LinkedIn Learning, 2019, p.19). On the one hand, such an approach makes a learner responsible for his/her professional and personal development journey increasing engagement with learning within the system of corporate education. On the other hand, L\&D organisations work towards closing those skills gaps which are required for company's development according to its strategic goals. Constant need in soft skills training remains one of the prevailing $L \& D$ trends related to the competitive market of soft skillsbased jobs with the emphasis on a precise assessment of the areas for employees' improvement in order to increase engagement with learning activities in companies (ibid.).

Understanding the impact of technology is of paramount importance in the age of digitalisation and rapid technological changes. Cameron Bishop (2018) argues that technologies in corporate education are of great importance for enabling learning in a fast-paced environment when time is of great value. To give employees the opportunity to access learning content anytime and anywhere, organisations should understand the importance of enabling learning on mobile devices.

Among Ukrainian researchers, the trends in corporate education were partially covered by Tatomyr (2016) in the scope of research of global trends in e-learning and mobile learning, Kalenyuk and Panchenko (2018) through investigating the phenomenon of corporate university and knowledge economy. Banit (2015) analyses tendencies in corporate education at global and organisational levels with the former one including tendencies for self-development and self-studies, increasing investments into HRD, high demand in qualified workforce, and considering learning preferences of a new generation.

Learning trends at workplace in Canadian companies are monitored and defined by a number of governmental and private research and analytical organisations. Among them, the most authoritative ones are the Statistics Canada, the Conference Board of Canada, and the Brookfield Institute. The Conference Board of Canada is a national research institution publishing annual comprehensive reports on the state of L\&D Industry, the latest one "Learning Cultures Lead the Way: Learning and Development Outlook-14th Edition" analysing the state of the learning and development industry in the country (Cotsman \& Hall, 2018). The Brookfield Institute aims at fostering innovation across Canada by conducting insightful research and 
analytics both cross-sectoral, e.g. analysis of talent gaps across the country (Tibando \& Do, 2018), and distributed by industry, e.g. the report on Canada's developers talent (Lamb, Rubinger, 2017).

The aim of the paper is to find out how current L\&D trends are followed by Canadian corporations and what their attitude to continuous learning is, considering that corporate narratives of official documentation are relevant object for research. At the same time, applying content analysis method to reach the aim allows us to approve or disapprove the hypothesis that corporate reports reflect the attitude of a respective organisation to employees' learning and development. The following objectives have been outlined: to conduct content analysis of the sampled documentation issued by Canadian companies; to benchmark Canadian a companies against current L\&D trends based on the analysis; to outline main findings related to the type of reports under the analysis as well as industries represented by the companies under the research.

The next sections of the paper present a detailed overview of research methods as applied in the research, explanation of the coding scheme elaborated for the investigation, quantitative and qualitative results of content analysis. Discussion section proceeds with the interpretation of the results and outlining correlations between the results of the analysis and current L\&D trends as outlined in the literature review. After a brief overview of the major limitations of the analysis, the paper wraps up with conclusions on how current L\&D tendencies are followed by the represented Canadian companies and whether sampled documentation is a sufficient source to retrieve such information.

\section{Methods}

The research employs a combination of qualitative and quantitative methods. In the centre of the methodological framework is qualitative content analysis as a "technique for making inferences by systematically and objectively identifying specific characteristics of messages" (Holsti, 1968, p. 601). Combination of conceptual and relational analysis is used in our research to reveal the existence and frequency of the concepts and their inter-relations in selected documentation. Applying logical, comparative, and descriptive methods enabled effective study and interpretation of concepts under research in their interrelations.

We rely on convenience sampling, rather than purposive one (Liamputtong, 2019), due to the fact that there is a lack of publicly available corporate documentation dedicated to talent development strategies and/or learning processes within organisations. At the same time, a homogeneous approach to sampling allowed us to draw valid conclusions on the formulated research hypothesis.

The research has been conducted using a sample of 21 annual reports of thirteen biggest Canadian companies. The list of companies and the reports is presented in Appendix 1. The selection of companies is based on 2019 Fortune 500 list compiled by Fortune, an authoritative global media organisation ranking companies by revenues per year (Fortune, 2020). Companies were defined as Canadian if they were founded in Canada and their headquarter was located there.

Two types of annual reports have been chosen for analysis due to their comprehensive coverage. General annual reports cover all major aspects of the company's development through the year. All 13 companies disclosed relevant information for 2019 and made them publicly available on their corporate websites. Other reports issued by the majority of companies are sustainability or ESG (Environment, Social and Governance) reports covering “company's social, environmental, governance and economic performance as well as communicating the company's values, priorities and action plans" (Chartered Professional, 2013, p. i). Unlike general annual reports, sustainability reporting is not mandatory, and in 2019, 8 companies out of 13 under the research issued these documents. ESG Reports constitute particular interest for our research because they are considered as "a broad reflection of a company's culture" and employees have been regarded as their main stakeholder group (ibid., p. 7).

Coding of the text narratives was conducted in two stages. Firstly, 3,035 pages of the reports were initially scanned to reveal the text excerpts related to corporate learning directly or indirectly. For this purpose, initial umbrella-code "learning, education, training, people development" was used. As the Anglophone literature utilises these terms interchangeably in relation to learning and development in organisations (Lytovchenko, 2020, p. 65), it was decided to use all of them as keywords for identifying text excerpts related to organisational learning.

The second stage of the content analysis relied on the coding scheme which was created partially in the process of the very coding. Methods of classification and generalisation enabled creating a hierarchy of codes for effective analysis. The scheme was drawn both deductively from the topic of inquiry, namely corporate learning and development trends as well as from existing research literature on the issue, and inductively in the course of coding and explained in detail in the next section of the paper. 
Preliminary analysis of the sampled texts complemented the list with the codes which were not predefined but were related to the aim of our research and helped formulate the conclusions more clearly. Text narratives were referenced with more than one code in case they were related to several subject areas. Initial codes which have not found their representation in the sample texts are not analysed in the scope of this paper.

To mitigate the probability of coding errors related to processing big volume of data, NVivo software has been used to facilitate the process of elaborating the coding scheme and quantifying the code. The results are discussed further and presented in the Table.1.

To interpret meaning from the content, we combined directed and summative approaches to content analysis as described by Hsein and Shannon (2005) since on the one hand, we are guided by existing theory on the subject of our research, and on the other hand, we rely on quantifying selected words and content in the sampled narratives for more precise analysis of their contextual use.

\section{Results}

Preliminary scanning of annual reports by the sampled Canadian companies revealed narratives of different length directly or indirectly related to learning or development of personnel which were referenced 811 times during the next stage of the analysis.

For compiling the list of initial codes, we relied on current research related to $L \& D$, particularly trends in the industry and principles of continuous professional development and learning. The review of literature on current trends in the sphere of corporate education allowed us to single out the following codes: "continuous learning", "alignment of L\&D and business strategy", "increasing investment in L\&D", "lack of time for learning", "self-directed learning", "developing interpersonal skills", "skills assessment", "learning technologies".

The pre-defined coding scheme was partly re-arranged in the process of coding. The initial code "lack of time for learning" was substituted with "training time" as none of the reports mentioned the issue of time scarcity while some of them disclosed training hours per year. Though skills assessment is considered an L\&D trend of 2019, no mentions of it were found during content analysis of the reports. Further study of the broader sample or other corporate report types might shed the light on the issue. "Compliance training" and "inclusion \& diversity training" were added as many narratives were related to these topics. As a result, the final list of parent codes is as follows: Continuous Development, Alignment of L\&D and Business Strategy, Compliance Training, Inclusion \& Diversity Training. Comprehensive coding scheme is presented in the Table 1.

With the biggest number of coding references (492), continuous development is regarded as an important L\&D issue in organisations. Though explicitly it is mentioned 80 times, implicitly the importance of continuous development is mentioned in the scope of other issues. The most references (201) are related to upskilling and reskilling of employees. A relatively big number of narratives was specific about the skills which were in the focus of $L \& D$ in the company, namely leadership development (42 references), technological acumen and digital literacy (31), as well as interpersonal skills (15).

All companies stress the necessity of being prepared to challenges of the future and continuous learning of personnel through developing emerging skills (46 references). Self-directed learning (21), especially facilitated with technologies, is considered as one of the most effective ways for professional development. Substantial attention is paid to early-career professionals and university graduates. The reports contain information on partnerships with educational institutions (15 references) as well as stand-alone projects initiated by companies (61).

Though, as it was previously mentioned, scarcity of time for learning cannot be stated as an issue for the organisations under the research based on the analysis of their reports, time spent for learning is regarded as an important metrics for L\&D effectiveness evaluation. Training time is mentioned 10 out of 10 times in Sustainability Reports of the companies.

Alignment of corporate education with business strategy is the second biggest segment of coded references. Content analysis of the reports and elaboration of the coding scheme shed the light on contexts intrinsically connected with this global L\&D trend. Nine reports revealed that personnel development is a valued aspect of organisational culture and inscribed in corporate values. Unleashing the potential of employees (55 references) is regarded as a safe road to remaining sustainable and competitive. With increasing investments into $L \& D$ around the world, Canadian biggest companies are not lagging behind and consistently invest into development of their personnel (44 references).

An interesting case is observed in relation to Compliancy Training represented more broadly in general annual reports (58\%) than in documentation on sustainability $(42 \%)$. Such topics as risk management, 
information security, code of conduct are extremely important issues highlighted in annual reports which are addressed mainly to present and prospective clients and shareholders who are ensured about the security of their cooperation with these corporations. This assumption can be supported with word frequency analysis results, where "risk" is the second most frequently used word (8,441 instances of usage) after "assets" in general annual reports and the sixth (1197 instances) in sustainability reports.

I\&D Training is closely related to Compliancy Training as many organisations make it mandatory for all their employees. Our analysis has revealed that, though I\&D is mentioned in general annual reports, the training in this area is reflected only in sustainability reports. In most cases, I\&D is embedded into corporate values, therefore, learning activities in this sphere are directly addressed in the analysed reports the biggest number of times (48) and can be associated with the necessity to align L\&D and business strategy. Training about the inclusion of indigenous people is highlighted by all but one companies with training for empowering women and LGBTQ+ community coming the second and the third respectively. Inclusion of the disabled employees is mentioned only once in the scope of training activities.

Table 1. Number of coding references distributed throughout the coding scheme and types of report

\begin{tabular}{|c|c|c|c|c|}
\hline Codes & $\begin{array}{c}\text { Aggregate } \\
\text { number of reports } \\
\text { coded }\end{array}$ & $\begin{array}{l}\text { Aggregate } \\
\text { number of coding } \\
\text { references }\end{array}$ & $\begin{array}{c}\text { Coding } \\
\text { references in } \\
\text { Annual Reports, } \\
\% \\
\end{array}$ & $\begin{array}{c}\text { Coding } \\
\text { references in } \\
\text { Sustainability } \\
\text { Reports, \% } \\
\end{array}$ \\
\hline Continuous Development & 19 & $\begin{array}{c}492 \\
(80 \text { directly) }\end{array}$ & $17 \%$ & $\mathbf{8 3} \%$ \\
\hline Upskilling \& reskilling & 17 & 201 & $17 \%$ & $83 \%$ \\
\hline Preparing for the future & 13 & 46 & $20 \%$ & $80 \%$ \\
\hline Leadership development & 6 & 42 & $7 \%$ & $93 \%$ \\
\hline Tech Acumen and Digital Literacy & 7 & 31 & $16 \%$ & $84 \%$ \\
\hline Self-directed learning & 5 & 21 & $0 \%$ & $100 \%$ \\
\hline Technology-enhanced learning & 8 & 15 & $0 \%$ & $100 \%$ \\
\hline Educating young people & 8 & 16 & $19 \%$ & $81 \%$ \\
\hline Partnership with universities & 7 & 15 & $31 \%$ & $69 \%$ \\
\hline Interpersonal skills & 11 & 15 & 0 & $100 \%$ \\
\hline Training time indicated & 4 & 10 & $0 \%$ & $100 \%$ \\
\hline $\begin{array}{l}\text { Alignment of L\&D and Business } \\
\text { Strategy }\end{array}$ & 19 & $\begin{array}{c}132 \\
\text { (23 directly) } \\
\end{array}$ & $22 \%$ & $\mathbf{7 8} \%$ \\
\hline Unleashing people's potential & 15 & 55 & $16 \%$ & $84 \%$ \\
\hline Investing in People & 12 & 44 & $23 \%$ & $77 \%$ \\
\hline Corporate values & 9 & 10 & $30 \%$ & $70 \%$ \\
\hline Compliance Training & 15 & $\begin{array}{c}116 \\
\text { (49 directly) }\end{array}$ & $\mathbf{5 8} \%$ & $42 \%$ \\
\hline Code of Conduct training & 11 & 25 & $40 \%$ & $60 \%$ \\
\hline Risks management training & 9 & 23 & $87 \%$ & $13 \%$ \\
\hline $\begin{array}{l}\text { Cyber- and information security } \\
\text { training }\end{array}$ & 9 & 13 & $62 \%$ & $38 \%$ \\
\hline Healthcare \& safety training & 3 & 6 & $0 \%$ & $100 \%$ \\
\hline Inclusion \& Diversity Training & 12 & $\begin{array}{c}71 \\
\text { (48 directly) } \\
\end{array}$ & $12 \%$ & $\mathbf{8 8} \%$ \\
\hline First Nations training & 2 & 11 & $0 \%$ & $100 \%$ \\
\hline Gender equality training & 5 & 9 & $0 \%$ & $100 \%$ \\
\hline LGBTQ+ training & 2 & 2 & $0 \%$ & $100 \%$ \\
\hline The disabled training & 1 & 1 & $0 \%$ & $100 \%$ \\
\hline
\end{tabular}


Apart from revealing the most widely covered aspects of $L \& D$ in corporate documentation, the analysis showed that sustainability reports reflect issues related to employee development more broadly than general annual reports. As presented in Table 1,83\% of narratives related to continuous development are drawn from sustainability reports. A similar situation is observed for alignment of L\&D and business strategy. The only aspect of corporate training referenced more times in general reports is compliance training even though health \& safety direction is presented only in sustainability reports.

One more interesting correlation to be highlighted in this research is the one between coded references and industries represented by the sampled companies, namely Finance and Banking, Oil and Gas, Automotive, Insurance, and Retail. The analysis has shown that documentation of Banking \& Finance companies contains $63 \%$ of all coded references of our study. Within continuous development represented the most extensively, the greatest segment is related to the necessity of predicting future challenges and upskilling employees. The lowest percentage of references is found in the reports of the Automotive and Retail industries: 8 and 6\% respectively. Oil\& Gas and Insurance industries are in the middle: 21 and 12\% respectively. It is worth noting that Compliance Training has broader representation in the documentation of Oil \& Gas and Automotive companies whereas I\&D Training is most diversified in Banking \& Finance companies.

\section{Discussion}

The results of the content analysis showed that the hypothesis formulated in the beginning of this study is confirmed: corporate narratives in official documentation can be regarded resourceful for study of L\&D within an organisation. The analysis also revealed that documentation on sustainability covers issues related to talent learning and development more broadly than general annual reports. This might be connected with differences in the main purposes and stakeholder groups of the reports. We can also state that analysed official narratives reflect such current global L\&D trends defined by the Association for Talent Development (ATD, 2019) as understanding the importance of continuous learning and development, alignment of L\&D and business strategy, increasing investment in employees' learning.

Though lack of time for training is not mentioned in the analysed texts, training hours is considered an important metrics for effectiveness evaluation of L\&D function and it is mentioned exclusively in sustainability reports. This can be explained by the fact that one of the main stakeholder groups of the reports is employees of the company on contrary to annual reports whose target groups are shareholders and clients. Information on training time is considered to be valuable for attracting and retaining talent.

While soft skills development has remained one of the most topical areas for L\&D in organisations, Canadian companies emphasise the importance of digital literacy due to rapid technological disruption and constant changes of the job market. According to the PricewaterhouseCoopers (PwC) Canada Report on Digital IQ, many organisations are struggling with the fast pace of technological change underlying the importance of developing skills in the domains of digital strategy, cybersecurity, data analytics. In 2017, almost 50 per cent of Canadian companies experienced lack of digitally skilled workforce to implement strategic initiatives and reach business goals (PwC Canada, 2017). Therefore, the biggest Canadian corporations put a lot of efforts into development of this skillsets and ensuring that their workforce is able to keep up with rapid technological changes. Additionally, work-integrated learning, co-ops, and internships are gradually becoming an integral part of educational journey of young professionals as Canadian companies experience a lack of essential skills of employees at the career entry-level.

It is worth noting that companies in the finance \& banking industry highlight the importance of constant learning and development more broadly than in other industries presented. It might be connected with more rapid technological disruption and demand for talent with strong interpersonal skills. Predominance of Finance \& Banking industry throughout our analysis also results from its broader representation among Fortune 500 Canadian companies.

As to Oil \& Gas and Automotive companies, we can assume that compliance training is more represented in narratives of these companies due to the fact that it is much more diversified, and people's lives literally depend on its effectiveness. As to I\&D training, which was revealed in the process of coding, it is still represented too narrowly in comparison with other categories, therefore it should be researched more profoundly in the extended reports sample. Additionally, due to their mandatory presupposition, we consider the discussion of compliance and I\&D training out of the scope of detailed discussion in thescope of this research.

Further research of the issues discussed in this paper can take several directions. Firstly, the method of content analysis of corporate documentation should be complemented with discourse analysis as it will allow interpretation of concepts in contexts more comprehensively. Secondly, other types of reports should be 
analysed with understanding that there is a considerable limitation related to their accessibility and confidentiality. Thirdly, representation of industries should be expanded for a holistic approach to study corporate learning and development in Canada. Fourthly, extending a time span for the purpose of comparative analysis would enable studying corporate education development in retrospective.

\section{Limitations}

It is assumed that the research results might be influenced by several limitations. Firstly, while the volume of text material is sufficient for content analysis, the representation of Canadian companies might be too limited to build assumptions per industry as, for instance, insurance and automotive industries are represented by only one company each. The investigation of a broader range of companies to draw more generalised conclusions is necessary.

Another limitation of this study relates to the selection of official documentation for the analysis. The research should be also expanded to other types of corporate reports related to human resource development strategies which, as a rule, are not publicly available and, thus, accessing them constitutes a problem.

Lastly, the method of content analysis, per se, presupposes the possibility of coding errors which might occur while processing big volumes of data. The analysis also does not exclude the authors' subjective perception of the concepts under investigation in different contexts.

\section{Conclusions}

The presented content analysis of annual and sustainability reports issued publicly by the biggest Canadian companies showed that corporate documentation contains relevant information on learning and development within organisations. At the same time, the investigation revealed that sustainability reports allow a more profound analysis of corporate education issues as they are addressed inter alia to employees and thus cover learning and talent development more broadly than general annual reports usually targeted at clients and shareholders.

Official narratives under the research reflect some of $L \& D$ trends as outlined by authoritative organisations in the industry. We have come to the conclusion that Canadian companies place high importance upon continuous learning with a strong emphasis on upskilling and reskilling of personnel with the main aim to keep up with rapid changes and technological disruption. For the same reason, interpersonal skills and digital literacy are singled out as the most needed skillsets for development. A lot of attention is paid to continuous development throughout the whole career, starting from preparation of graduates and early career professionals. Another L\&D trend reflected in the analysed reports is an alignment of L\&D function and business strategies of the companies which are mostly represented with the information on corporate values, increasing investment into workforce development, and unleashing people's potential.

While the analysis revealed a lot of coded references on compliance and inclusion \& diversity training, these aspects are not considered as L\&D trends due to their mandatory nature and should be considered for further research.

All in all, the findings of our study complement the research of Canadian corporate education and should be proceeded with the analysis of the more diversified sample in terms of representation of industries and documentation types. Discourse analysis should be considered for further investigation of corporative narratives in different contexts as it will allow drawing more comprehensive conclusions on the state of L\&D industry in Canada.

\section{References:}

ATD (2018). Lifelong Learning. The Path to Personal and Organisational Performance. ASTD DBA Association for Talent Development (ATD)

ATD (2019). 2019 Global Trends in Talent Development Whitepaper. ASTD DBA Association for Talent Development (ATD).

Banit, O. (2015). Suchasni tendentsii profesiinoho rozvytku personalu v systemi korporatyvnoi osvity. [Modern Tendencies of the Staff Professional Development in the System Of Corporate Education]. Osvita doroslykh: teoriia, dosvid, perspektyvy, 2 (11), 28-38.

Bass, B. M. (1991). From Transactional to Transformational Leadership: Learning to Share the Vision. Organisational dynamics, 18 , 19-31. https://doi.org/10.1016/0090-2616(90)90061-S

Bersin, J. (2018). LinkedIn Learning: A Bold Success With More Growth To Come. Retrieved January 12, 2020, from https://www.linkedin.com/pulse/linkedin-learning-bold-success-more-growth-come-josh-bersin/

Billett, S., Harteis, C. \& Gruber, H. (2014). International Handbook in Professional and Practice-Based Learning. Springer, Dordrecht. https://doi.org/10.1007/978-94-017-8902-8

Bishop, C. (2018). Seven Learning And Development Trends To Adopt In 2019. Forbes. Retrieved January 20, 2020, from https://www.forbes.com/sites/forbeshumanresourcescouncil/2018/09/24/seven-learning-and-developm ent-trends-to-adoptin-2019/\#2e153998104b 
Chartered Professional Accountants of Canada. (2013). A Starter's Guide to Sustainability Reporting. Retrieved June 12020 from https://www.cpacanada.ca/en/business-and-accounting-resources/financial-and-non-financial-reporting/sustainabilityenvironmental-and-social-reporting/publications/a-starters-guide-to-sustainability-reporting

Cotsman, S., \& Hall, C. (2018). Learning Cultures Lead the Way: Learning and Development Outlook (14th Ed.). Ottawa: The Conference Board of Canada. Retrieved January 19, 2020, from https://www.conferenceboard.ca/elibrary/abstract.aspx?did=9398\&Aspx AutoDetectCookieSupport=1

Coursera for Business. (2018). Learning \& Development from Both Sides of the Table 21 Insights to Maximize Your L\&D Investment. Retrieved January 12, 2020, from https://www.coursera.org/business

Craig, R. J., \& Brennan, N. M. (2012). An exploration of the relationship between language choice in CEO letters to shareholders and corporate reputation. Accounting Forum, 36, 166-167. https://doi.org/10.1016/j.accfor.2012.02.004

Fortune. (2020). Methodology for Fortune 500. Retrieved May 18, 2020, from https://fortune.com/franchise-list-page/fortune-500methodology-2020/

Higgins, C. \& Walker, R. (2012). Ethos, logos, pathos: strategies of persuasion in social/environmental reports. Accounting Forum, 36, 194-208. https://doi.org/10.1016/j.accfor.2012.02.003

Holsti, O. R. (1968). Content Analysis. In L. Gardner \& A. Elliot (Eds.), The Handbook of Social Psychhdogv: Research Methods, Vol.2 (pp. 596-692). Reading MA: Addism-WesIey.

Hossain D. M. (2017). Discourse Analysis: An Emerging Trend in Corporate Narrative Research. Middle East Joumal of Business, 12(4), 3-9. https://doi.org/10.5742/MEJB.2017.93084

Hsein, H.-F., Shannon, S. E. (2005). Three approaches to qualitative content analysis. Qualitative Health Research, 15 (9). $1277-$ 1288. https://doi.org/10.1177/1049732305276687

Kalenyuk, I., \& Panchenko, E. (2018). Korporatyvni formy pidhotovky personalu v umovakh ekonomiky znan [Corporate Forms of Personnel Training in a Knowledge Economy]. Rynok pratsi ta zainiatist naselennia, 2(55), 53-61.

Knowles, M. (1975). Self-Directed Learning: A Guide for Learners and Teachers. Chicago, IL: Follett Publishing Company. https://doi.org/10.1177/105960117700200220

Lamb, C., Rubinger, D. (2017). Stacking Up: A snapshot of Canada's developer talent. Brookfield Institute for Innovation + Entrepreneurship. Retrieved January 31, 2020, from https://brookfieldinstitute.ca/wpcontent/uploads/BrookfieldInstitute_StackingUp.pdf

Liamputtong, P. (2019). Qualitative Research Methods, fifth edition. Australia:Oxford University Press.

LinkedIn Learning. (2019). 3rd Annual 2019 Workplace Leaning Report. Retrieved January 12, 2020, from https://learning.linkedin.com/content/dam/me/business/en-us/amp/learning-solutions/images/workplace-learning-report2019/pdf/workplace-learning-report-2019.pdf

Lytovchenko, I. (2020). Korporatyvna osvita u Spoluchenykh Shtatakh Ameryky: Teoriia i praktyka [Corporate education in the United States of America: Theory and Practice]. Kyiv.

Merkl-Davies, D.M., \& Brennan, N.M. (2011). A conceptual framework of impression management: new insights from psychology, sociology and critical perspectives. Accounting and Business Research, 41(5), 415-437. https://doi.org/10.1080/00014788.2011.574222

PwC Canada. (2017). Digital IQ 2017-Canadian Insights. Retrieved January 21, 2020, from https://www.pwc.com/ca/digitaliq

Scharf, E. R. \& Fernandes, J. (2012). The advertising of corporate social responsibility in Brazilian bank. International Journal of Bank Marketing, 31(1), 24-37. https://doi.org/10.1108/02652321311292038

Schwab, K. (2019). The Global Competitiveness Report 2019. Retrieved March 15, 2020, from http://www3.weforum.org/docs/WEF_TheGlobalCompetitivenessReport2019.pdf

Tannenbaum, S. I. (1997). Enhancing continuous learning: diagnostic findings from multiple companies. Human Resource Management, 36 (4), 437-452. https://doi.org/10.1002/(SICI)1099-050X(199724)36:4<437::AID-HRM7>3.0.CO;2-W

Tatomyr, I. (2016). Hlobalni trendy rozvytku rynku elektronnoho navchannia. [Global Market Trends of E-Learning]. Skhidna Yevropa: Ekonomika, biznes ta upravlinnia, 2 (02), 58-65.

Tibando, A., Do, A. (2018). Understanding the Talent Gap: Lessons + Opportunities for Canada. A Discussion Paper. Brookfield Institute for Innovation + Entrepreneurship. Retrieved January 21, 2020, from https://brookfieldinstitute.ca/wpcontent/uploads/BrookfieldInstitute_Understanding-the-Talent-Gap-1.pdf 


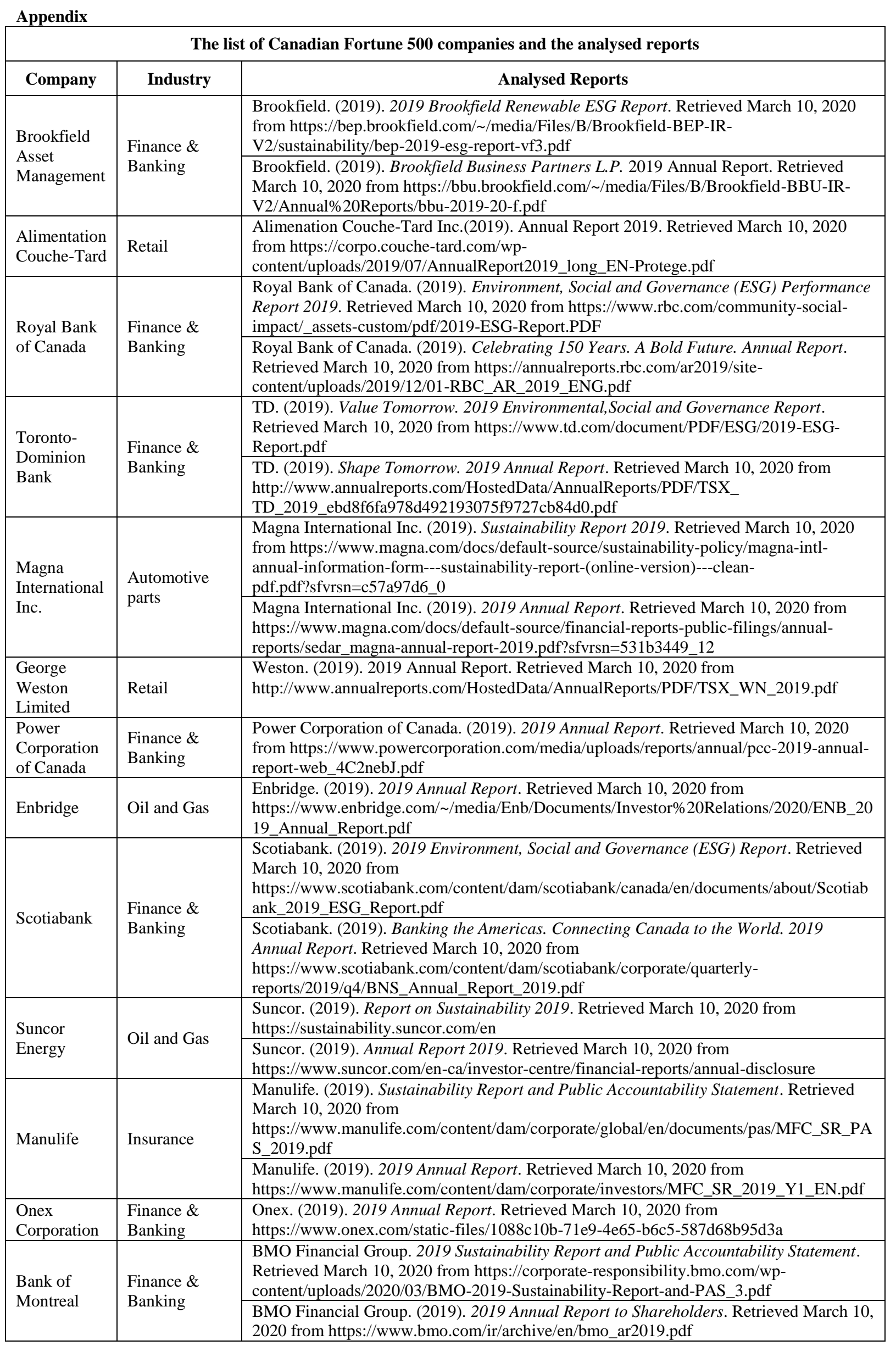

